\title{
Enthalpic Contribution of Ni(II) in the Interaction between Carbonaceous Material and Aqueous Solution
}

\author{
Liliana Giraldo ${ }^{1}$ and Juan Carlos Moreno-Piraján ${ }^{2}$ \\ ${ }^{1}$ Departamento de Química, Facultad de Ciencias, Universidad Nacional de Colombia, Sede Bogotá, Colombia \\ ${ }^{2}$ Departamento de Química, Facultad de Ciencias, Universidad de Los Andes, Grupo de Investigación en Sólidos \\ Porosos y Calorimetría, Bogotá, Colombia
}

Correspondence should be addressed to Juan Carlos Moreno-Piraján; jumoreno@uniandes.edu.co

Received 22 February 2017; Revised 29 April 2017; Accepted 21 May 2017; Published 18 June 2017

Academic Editor: Christophe Coquelet

Copyright (C) 2017 Liliana Giraldo and Juan Carlos Moreno-Piraján. This is an open access article distributed under the Creative Commons Attribution License, which permits unrestricted use, distribution, and reproduction in any medium, provided the original work is properly cited.

Solid adsorbents were prepared from corn cob that was modified with a solution of $\mathrm{HNO}_{3} 6 \mathrm{M}$ at different contact times. The solids are characterized by physical $\mathrm{N}_{2}$ adsorption at $77 \mathrm{~K}$ to know their surface area by applying the BET model and surface chemistry is determined using the Bohem method. Once we have prepared the adsorbents we determine the immersion enthalpy, $\Delta H_{\mathrm{im}}$, of the solids in $\mathrm{Ni}(\mathrm{II})$ aqueous solutions of different concentrations between 20 and $800 \mathrm{mg} \cdot \mathrm{L}^{-1}$, with values for $\Delta H_{\text {im }}$ between 10.0 and $35.3 \mathrm{~J} \cdot \mathrm{g}^{-1}$. From the results obtained for the immersion enthalpy in function of the ion $\mathrm{Ni}$ (II) concentration we calculate the contribution to the immersion enthalpy that corresponds to the ion when it is treated with the system adsorbent-solution as a mixture in which the solid, the solvent, and the adsorbate are involved. The solution thermodynamics allows for establishing the enthalpic changes that bring the ion in function of the concentration and the intensity of the interaction of solid-metal ion that is favored by the presence of acid groups in the solid.

\section{Introduction}

The process of interaction between a solid and a liquid can be considered, in a simplified manner as a mixture of the two components of the system that produce changes in the thermodynamic properties with regard to the components before the interaction and the thermodynamic properties as enthalpy, entropy, and energy of Gibbs can be determined for mixing process [1].

The purpose of the thermodynamic properties determination of an interaction between various components is to know the intensity of the property and how it is affected in function of the mixture. So you can find woks that are related to the determination of excess enthalpy for organic compounds [2], determinations of partial molar enthalpy in the components of different alloys [3], excess molar enthalpies for binary systems of solvent-solute [4], among others. The methodology for the calculation of the partial thermodynamic properties, that is, the contribution of each component to the property thermodynamics total, can be extended to the solid-liquid interaction taking into account the particular characteristics of the solid and the interaction type that is being carried out. In this research the adsorption process of ion $\mathrm{Ni}$ (II) takes place on a carbonaceous material.

Myers and Monson [5] make an interesting discussion on the implementation of the solutions (mixtures) thermodynamics, to the adsorption process of a fluid component on a porous solid, and establish that by relatively simple way the formulation of mixtures thermodynamics can be extend to properties like the enthalpy differential for the adsorbent and the adsorbate.

1.1. Differential Enthalpy of the Mixture Components. The adsorbent-solution is a multicomponent system and for conditions of temperature $T$ and pressure $P$ specifically, the 
variation of a property thermodynamics considered $X$ (as the enthalpy for this case) can be expressed as

$$
\begin{aligned}
d X= & \left(\frac{\partial X}{\partial T}\right)_{P, n_{i}} d T+\left(\frac{\partial X}{\partial P}\right)_{T, n_{i}} d P+\left(\frac{\partial X}{\partial n_{1}}\right)_{T, P, n_{j}} d n_{1} \\
& +\left(\frac{\partial X}{\partial n_{2}}\right)_{T, P, n_{j}} d n_{2}+\left(\frac{\partial X}{\partial n_{3}}\right)_{T, P, n_{j}} d n_{3} .
\end{aligned}
$$

For the enthalpy system a similar expression is considered

$$
\begin{aligned}
d H= & \left(\frac{\partial H}{\partial T}\right)_{P, n_{i}} d T+\left(\frac{\partial H}{\partial P}\right)_{T, n_{i}} d P \\
& +\left(\frac{\partial H}{\partial n_{1}}\right)_{T, P, n_{j}} d n_{1}+\left(\frac{\partial H}{\partial n_{2}}\right)_{T, P, n_{j}} d n_{2} \\
& +\left(\frac{\partial H}{\partial n_{3}}\right)_{T, P, n_{j}} d n_{3},
\end{aligned}
$$

where

$$
\left(\frac{\partial H}{\partial n_{i}}\right)_{T, P, n_{j}}=\overline{H_{i}}
$$

corresponds to the partial molar enthalpy of component $i$ to $T, P$, and $n_{j}$ constant. The contribution of each one of the system components to the total enthalpy is established in this manner. Thus it is possible to determine experimentally a change in the enthalpy that manifests for the process that corresponds to the adsorbent-solution interaction and define the change in the enthalpy differential for each component of the mixture $\Delta H_{\mathrm{DIF}_{i}}$, as the difference between the partial molar enthalpy of component $i, \overline{H_{i}}$, and the molar enthalpy of component $i$ pure, $H_{i}^{*}$

$$
\Delta H_{\mathrm{DIF}_{i}}=\overline{H_{i}}-H_{i}^{\bullet}
$$

It is noted that we cannot determine absolute values of enthalpy, but we can determine the difference between the enthalpic content of component in the system and the pure component. The change in the differential enthalpy, $\Delta H_{\mathrm{DIF}_{i}}$, is also expressed as

$$
\Delta H_{\mathrm{DIF}_{i}}=\left(\frac{\partial \Delta H_{\mathrm{exp}}}{\partial n_{i}}\right)_{T, P, n_{j}} .
$$

Each system component makes a contribution to the mixture enthalpy and therefore the change in the enthalpy differential can be determined, because this property is a suitable tool to describe mixture properties and the changes that occur when changing, for example the components quantities [6].

When we calculate the enthalpy differential for the components of a mixture, as a solution or an alloy [7], variations in the thermodynamic property are expressed by mol in the mixture; however in the case of a mixture as that described in this work which determines the change in the experimental enthalpy for the mixture of carbonaceous solids, water, and ion $\mathrm{Ni}(\mathrm{II})$, the contribution cannot be calculated by mol but per gram of each system component.

In this work we determined the immersion enthalpy, $\Delta H_{\mathrm{im}}$, of the carbonaceous adsorbent materials in aqueous $\mathrm{Ni}$ (II) solutions of different concentrations and calculate the relationship of mass of $\mathrm{Ni}(\mathrm{II})$ with respect to the system mass, $X_{\mathrm{Ni}(\mathrm{II})}$, and the enthalpy change by $\mu \mathrm{g}$ of ion $\mathrm{Ni}(\mathrm{II})$, $\Delta H_{\text {exp }}$, from which we calculate the change in the differential enthalpy of $\mathrm{Ni}$ (II) in the mixture, $\Delta H_{\mathrm{DIF}_{\mathrm{Ni}} \text { (I) }}$. Established are correlations between, $\Delta H_{\mathrm{DIF}_{\mathrm{Ni} \text { (II) }}}$, the total acid groups content, and the carboxylic groups content on the solids surface with the purpose of observing the difference in behavior of dilute and concentrated solutions of $\mathrm{Ni}$ (II).

\section{Experimental and Methods}

2.1. Preparation and Characterization of the Carbonaceous Solids. The carbonaceous solid adsorbents are prepared from corn cob that is dried in an oven at $100^{\circ} \mathrm{C}$ and 5 hours later is crushed to a particle size of $4-5 \mathrm{~mm}$ and it chars in a horizontal oven for 1 hour in a nitrogen atmosphere to $450^{\circ} \mathrm{C}$, to increase the material porosity.

The carbonized solid is subjected to oxidation with a $\mathrm{HNO}_{3}$ solution $6 \mathrm{M}$ at $60^{\circ} \mathrm{C}$ and at different contact times of 3, 6, and 9 hours with the purpose that the surface increases the oxygenated groups content. Once the time established elapses the solids are washed with distilled water until a $\mathrm{pH}$ around 6.5. The solids are called CC by corn cob for solid without treatment acid and CCox followed by the contact time with the $\mathrm{HNO}_{3}$ solution.

The solids were characterized by means of the $\mathrm{N}_{2}$ adsorption at $77 \mathrm{~K}$ for the surface area and for determining the oxygenated groups content the method proposed by Boehm [8] is followed, to put $100 \mathrm{mg}$ of solid in contact with $50 \mathrm{~mL}$ of $\mathrm{NaOH}, \mathrm{Na}_{2} \mathrm{CO}_{3}$, and $\mathrm{NaHCO}_{3}$ solutions with concentration $0.1 \mathrm{M}$ and $50 \mathrm{~mL}$ of $\mathrm{HCl}$ solution $0.1 \mathrm{M}$; mixtures are kept at a temperature of $25^{\circ} \mathrm{C}$, with constant agitation, for five days. Finally $10 \mathrm{~mL}$ aliquots of solutions are titled in contact with the solid.

2.2. Determination of the Immersion Enthalpy. It uses a heat conduction microcalorimeter to determine the immersion enthalpy of the carbonaceous solids in aqueous $\mathrm{Ni}$ (II) solutions, which are prepared from $\mathrm{Ni}\left(\mathrm{NO}_{3}\right)_{2} \cdot 6 \mathrm{H}_{2} \mathrm{O}$ of the tradmark Merck with concentrations between 20 and $800 \mathrm{mgL}^{-1} .10 \mathrm{~g}$ of the solution at $25^{\circ} \mathrm{C}$ and a solid sample of $100 \mathrm{mg}$ are added to the calorimetric cell (weight with accuracy of $0.1 \mathrm{mg}$ ) that is placed inside the cell in a glass ampoule and starts the potential registration output from the thermal sensor for a period of approximately 15 minutes taking potential readings every 20 seconds; it is necessary to perform the breaking of the glass ampoule, record the thermal effect generated, and continue with the potential readings for approximately 15 more minutes; finally the system is calibrated electrically [9]. 
TABLE 1: Physiochemical characterization of the carbonized oxidized solids.

\begin{tabular}{lcccccc}
\hline Solid & $\begin{array}{c}\text { Surface area } \\
\left(\mathrm{m}^{2} \mathrm{~g}^{-1}\right)\end{array}$ & $\begin{array}{c}\text { Carboxylic groups } \\
\left(\mathrm{mmolg}^{-1}\right)\end{array}$ & $\begin{array}{c}\text { Phenolic groups } \\
\left(\mathrm{mmolg}^{-1}\right)\end{array}$ & $\begin{array}{c}\text { Lactonic groups } \\
\left(\mathrm{mmolg}^{-1}\right)\end{array}$ & $\begin{array}{c}\text { Total acidity } \\
\left(\mathrm{mmolg}^{-1}\right)\end{array}$ & $\begin{array}{c}\text { Total basicity } \\
\left(\mathrm{mmolg}^{-1}\right)\end{array}$ \\
\hline CC & 130 & 0.13 & 0.23 & 0.10 & 0.46 & 0.28 \\
CCox3 & 122 & 0.26 & 0.16 & 0.15 & 0.57 & 0.12 \\
CCox6 & 115 & 0.38 & 0.17 & 0.20 & 0.75 & 0.10 \\
CCox9 & 110 & 0.46 & 0.42 & 0.38 & 1.26 & 0.07 \\
\hline
\end{tabular}

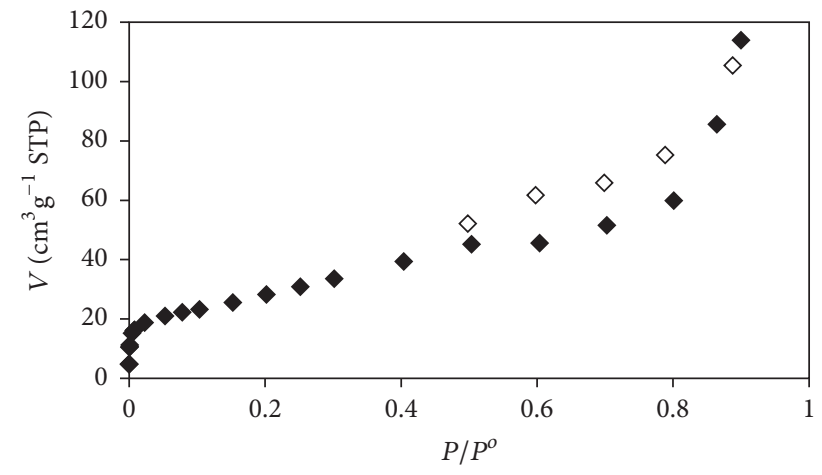

FIGURE 1: $\mathrm{N}_{2}$ adsorption isotherm for solid carbonaceous CC.

\section{Results and Discussion}

Once the carbonaceous solids that from the corn cob were prepared, these are characterized by $\mathrm{N}_{2}$ adsorption with the aim of knowing the surface area values and pores total volume using the BET model. Figure 1 shows the $\mathrm{N}_{2}$ adsorption isotherm for solid CC which is carbonized in an inert atmosphere.

For the carbonized CC a type IV isotherm is observed with hysteresis cycle that presents a plateau at relatively high pressures; in the adsorption branch a slope is observed high near the saturation and the desorption occurs at intermediate pressures. This characteristics type corresponds to a hysteresis cycle type $\mathrm{H} 3$ that is associated with capillaries in the slit form open with parallel walls and capillaries with wide bodies and short and narrow neck [10]. Solids that are subjected to oxidation with the $\mathrm{HNO} 3$ solution presented similar isotherms and the apparent surface area for these was determined by the BET model.

Table 1 presents the results obtained for the solids characterization in regard to their surface area values and the oxygenated groups content that are generated by the oxidation process that occurs in the carbonized solids.

According to the results the carbonized solids show surface area of similar values around $110 \mathrm{~m}^{2} \mathrm{~g}^{-1}$ that is slightly modified by the oxidation treatment because oxygen groups are generated in the surface that limit the incipient porosity produced by the carbonization process. It is observed that the greatest contact time between the solid and the nitric acid solution presents the solid with a higher content in groups of acid character, with a value of $1.26 \mathrm{mmolg}^{-1}$ and the smallest value for the total basicity. The results in regard to the surface groups content are comparable to a work in which activated carbons are prepared by chemical activation with $\mathrm{KOH}$ [11].

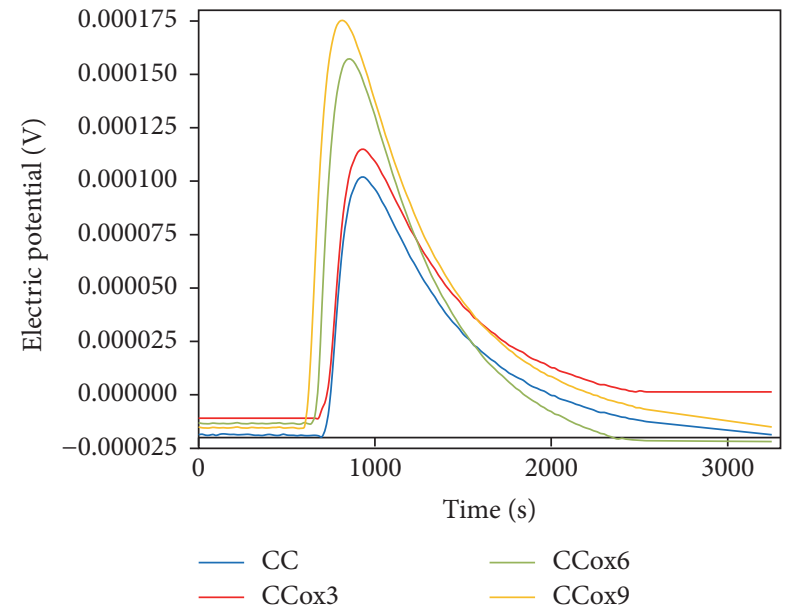

Figure 2: Immersion calorimetric curves of the carbonaceous solids in an aqueous ion $\mathrm{Ni}(\mathrm{II})$ solution of $100 \mathrm{mgL}^{-1}$.

The immersion enthalpy of the carbonaceous solids with mentioned characteristics in aqueous $\mathrm{Ni}(\mathrm{II})$ solutions is determined in a wide concentration range in order to observe the behavior with regard to the enthalpy change for immersion in dilute and concentrated solutions. Figure 2 presents the calorimetric curves that are obtained for the solids to an ion $\mathrm{Ni}(\mathrm{II})$ concentration of $100 \mathrm{mgL}^{-1}$.

The peak in the potential curve in function of time is proportional to the heat quantity that is generated in the solid-liquid contact. It is observed that the solid that presents the highest peak when immersed in the ion solution is the one that was submitted for oxidation for 9 hours and that has the highest acid groups content that have the ability to interact with the $\mathrm{Ni}(\mathrm{II})$, showing that the effect in the surface modification increases the immersion enthalpy of the solid in the solution [12]. The effect that occurs in the immersion increases the potential of the thermal sensor indicating that the process is of exothermic character and involving the interactions that occur between the three mixture components to be studied.

From curves like the ones shown in Figure 2 calculate the immersion enthalpy of solids in solutions that are tested in conditions of low and high dilution with the purpose of comparing the enthalpy change of the immersion process. Figure 3 presents the relation between the immersion enthalpy and the mass of ion $\mathrm{Ni}(\mathrm{II})$ present in the mixture along with water and the carbonaceous solid.

To appreciate the $\mathrm{Ni}(\mathrm{II})$ contribution to the total immersion enthalpy the solid adsorbent quantities and water must 


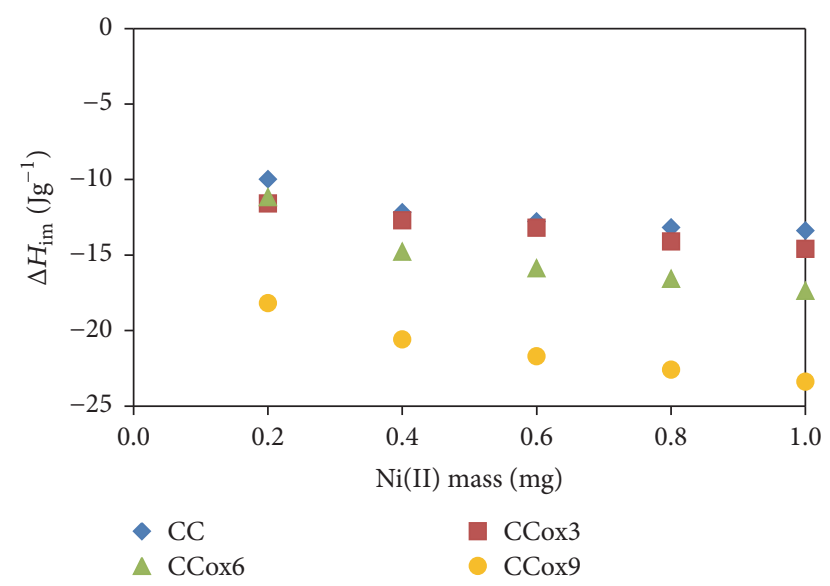

FIGURE 3: Immersion enthalpy of the carbonized solids in aqueous $\mathrm{Ni}(\mathrm{II})$ solutions in function of the ion mass.

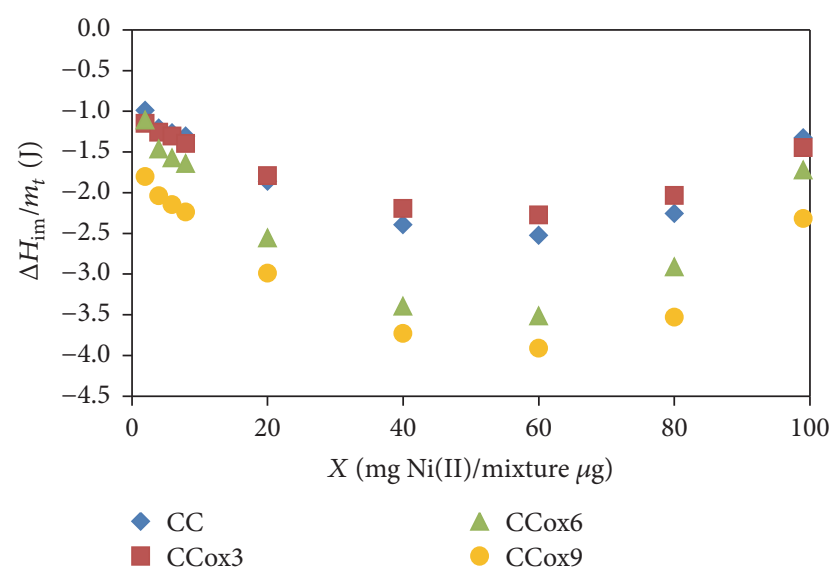

FIGURE 4: Immersion enthalpy per mixture mass as a function of the $\mathrm{Ni}(\mathrm{II})$ mass fraction.

be kept constant that acts as a solvent of smaller amount of ions that have a positive electrical charge [13]. Figure 3 shows the negative values of enthalpy change and exothermic character, which are greater for the two solids that were in contact with the $\mathrm{HNO}_{3}$ solution for 6 and 9 hours. The highest values of enthalpy indicate greater solid-liquid interaction, in that the solid to be oxidized during 3 hours shows a similar behavior to the carbonized one that had not been subjected to oxidation.

The ion $\mathrm{Ni}(\mathrm{II})$ contribution to the immersion enthalpy, $\Delta H_{\mathrm{im}}$, is calculated assuming that the system is a mixture of three components for which a mass relationship is established instead of a molar relationship (which would allow knowing the partial molar properties) since it does not know the moles of solid but if it is a mass, this defines the variable mass fraction, $X_{\mathrm{Ni}(\mathrm{II})}$, as the $\mathrm{Ni}$ (II) mass in the solution on the total mixture mass. In the same way we can calculate the solid and the solvent contribution to the enthalpy total change; however the ion contribution is of greater interest since that is the adsorbate [14]. Figure 4 shows the relation of $\Delta H_{\mathrm{im}} /$ mixture mass in function of the $\mathrm{Ni}(\mathrm{II})$ mass fraction for the range of concentrations which are studied.

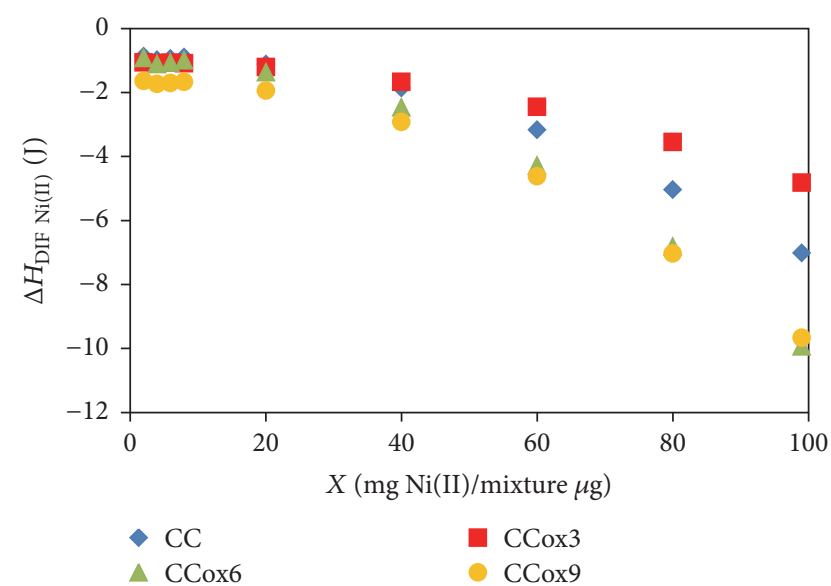

FIGURE 5: Ion Ni(II) differential enthalpy change in function of their mass fraction in the mixture.

Figure 4 shows curves for the four solids with peaks toward the mass fraction, $X_{\mathrm{Ni}(\mathrm{II})}$, around 60 and indicates different behaviors for the low and the high ion concentrations that indicate different interactions in the ion adsorption process on the solid that generates a enthalpy total change for the mixture.

From Figure 4 calculate the change in the Ni(II) differential enthalpy, $\Delta H_{\mathrm{DIF}_{\mathrm{Ni}(I)}}$, which corresponds to the partial derivative of the immersion enthalpy with regard to the mass fraction, $\left(\partial \Delta H_{\mathrm{im}} / \partial X_{\mathrm{Ni}(\mathrm{II})}\right)$, and represents the difference between the ion $\mathrm{Ni}$ (II) enthalpy when it is in the mix and the pure ion enthalpy. In this way it is stated that it is not possible to calculate the ion $\mathrm{Ni}$ (II) absolute enthalpy in the mixture but the difference between the two states. Figure 5 presents the results obtained for $\Delta H_{\mathrm{DIF}_{\mathrm{Ni}(\mathrm{II})}}$, in function of $X_{\mathrm{Ni}(\mathrm{II})}$.

Figure 5 is an interesting result because it shows that when increasing the ion $\mathrm{Ni}(\mathrm{II})$ quantity in the mixture its contribution to the total enthalpy becomes greater. For the dilute concentrations in the three solids CC, CCox3, and CCox6, the values are similar and note that overlap for the carbonized CCox 9 shows a greater change of enthalpy. For mass fractions of the ion greater than 20 (mg Ni(II)/ $/ \mu$ mixed) it is noted that the $\mathrm{Ni}$ (II) differential enthalpy increases with a greater contribution to the CC carbonized without treatment with respect to the one that was oxidized during three hours, while for solids with greater oxidation time this enthalpic contribution is similar. In this way by the calculation of the change in the ion differential enthalpy, $\Delta H_{\mathrm{DIF}_{\mathrm{Ni}(\mathrm{II})}}$, it is useful to see the difference in the interactions and the influence of the superficial oxygen groups in the solid adsorbent.

It is known that the interaction between metal ions that are in aqueous solution and a solid adsorbent has different influences, including the oxygen groups content of the solid surface [15]. For this reason once it is estimated the $\Delta H_{\mathrm{DIF}_{\mathrm{Ni}}(\mathrm{II})}$ relates to the content of carboxylic groups on the solid surface and with the total acidity that this presents. Figure 6 shows the result of such relationships in a diluted $\mathrm{Ni}$ (II) solution with a mass ratio $X$ of 2 , to an intermediate concentration solution of ion, with an $X 40$, and a ion concentrated solution. 


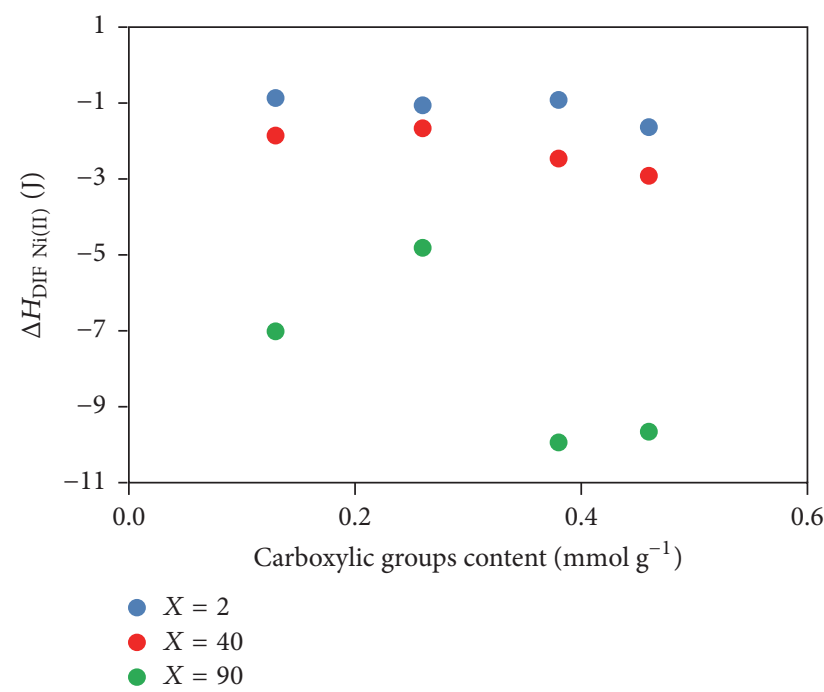

(a)

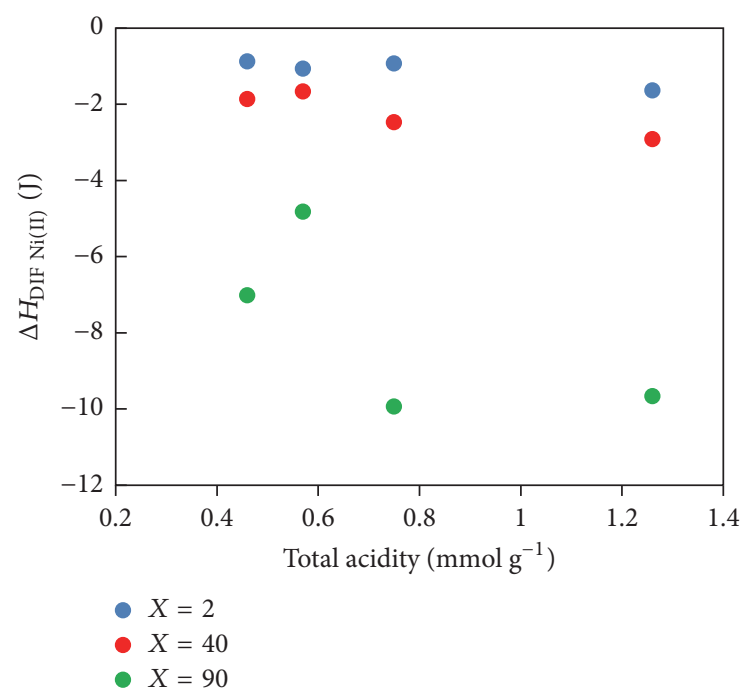

(b)

FIGURE 6: Ion $\mathrm{Ni}(\mathrm{II})$ differential enthalpy change, $\Delta H_{\mathrm{DIF}_{\mathrm{Ni}}(\mathrm{II})}$, in function of the oxygen content groups on the carbonized surface. (a) Carboxylic groups content, (b) total acidity.

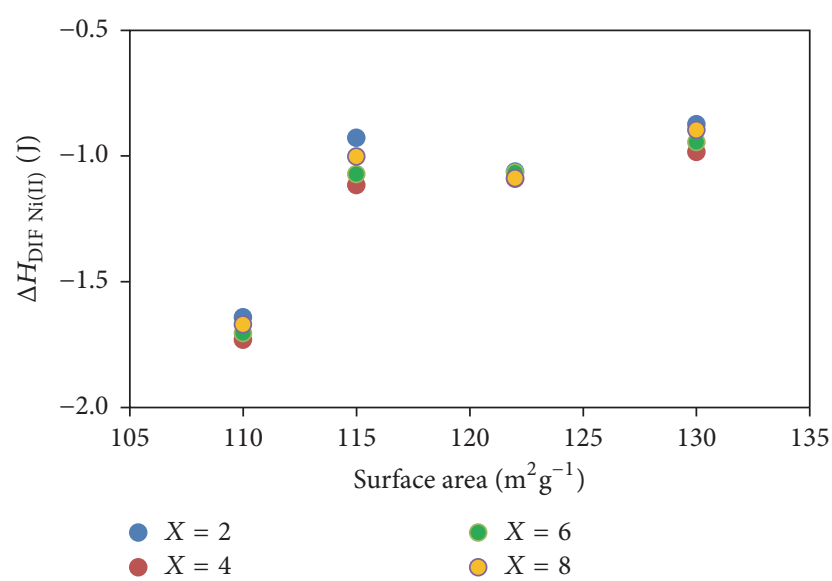

FIGURE 7: Ion Ni(II) differential enthalpy change in function of the carbonized surface area.

Relations show a similar behavior for the solutions with mass fractions of 2 and 40 for the change in the differential enthalpy ion are between -0.87 and $-1.73 \mathrm{~J}$ but when the ion concentration increases the change in the enthalpy becomes larger and is marked by two trends: for the carbonized less oxidized solids the difference of enthalpy decreases and for solids with greater oxidation values the enthalpy differential is nearby; the above indicates that the solid interactions with ion in the mixture are intensified with the presence of oxygen groups, as shown by different works that determine the metal ions adsorption capacity in aqueous solution on solid adsorbents [15-17]. It is noted that $\Delta H_{\mathrm{DIF}_{\mathrm{N} \text { (II) }}}$ is sensitive to the ion quantity present in the mixture and to the solid surface chemistry.

As the other characteristic of the solids that generates an energetic contribution in the mixture the surface area in Figure 7 shows the relation between the $\Delta H_{\mathrm{DIF}_{\mathrm{Ni}} \text { (I) }}$ and the carbonized surface area.
The results show that the higher values for $\Delta H_{\mathrm{DIF}_{\mathrm{Ni}} \text { (II) }}$ are to the carbonized CCox9 that presented the lowest value of surface area $\left(110 \mathrm{~m}^{2} \mathrm{~g}^{-1}\right)$ and the highest oxygen groups content confirming the fact that the oxygen groups in the carbonized solids interact with the ion to a greater extent than the single attraction of the surface. For the carbonized CCox3 differential enthalpy values are obtained similar between -1.06 and $-1.09 \mathrm{~J}$ for different quantities of the ion in the mix, which can indicate effects compensation on the solidion interaction.

As in the mixture that is considered the solid and the solvent quantities have remained constant, by application of the Gibbs-Duhem equation:

$$
\begin{gathered}
\left(X_{\text {sólido-solvente }}\right)\left(\frac{\partial \Delta H_{\mathrm{DIF}_{\text {solido-solvente }}}}{\partial X_{\mathrm{Ni}(\mathrm{II})}}\right) \\
+\left(X_{\mathrm{Ni}(\mathrm{II})}\right)\left(\frac{\left.\partial \Delta H_{\mathrm{DIF}_{\mathrm{N} \text { (III) }}}\right)}{\partial X_{\mathrm{Ni}(\mathrm{II})}}\right)=0 .
\end{gathered}
$$

This expression indicates that the variations of the partial quantities, in this case the change in the enthalpy differential, with regard to the system composition are not independent of a temperature and constant pressure [13]. Using (6) we can calculate the differential enthalpy change for solid and solvent in the mixture and this in function of ion $\mathrm{Ni}$ (II) mass fraction presents a behavior contrary to the ion $\mathrm{Ni}$ (II) differential enthalpy change, $\Delta H_{\mathrm{DIF}_{\mathrm{Ni}(\mathrm{II})}}$, as what happens with the partial molar properties in the development of the mixture thermodynamics. Figure 8 presents the results obtained for these relations to the CC carbonized without acid treatment CC.

Presenting the two trends in the enthalpy differential change, most of the values show exothermic character, and note that the change in the ion differential enthalpy increases when that of the set solid-solvent decreases. Also shown 


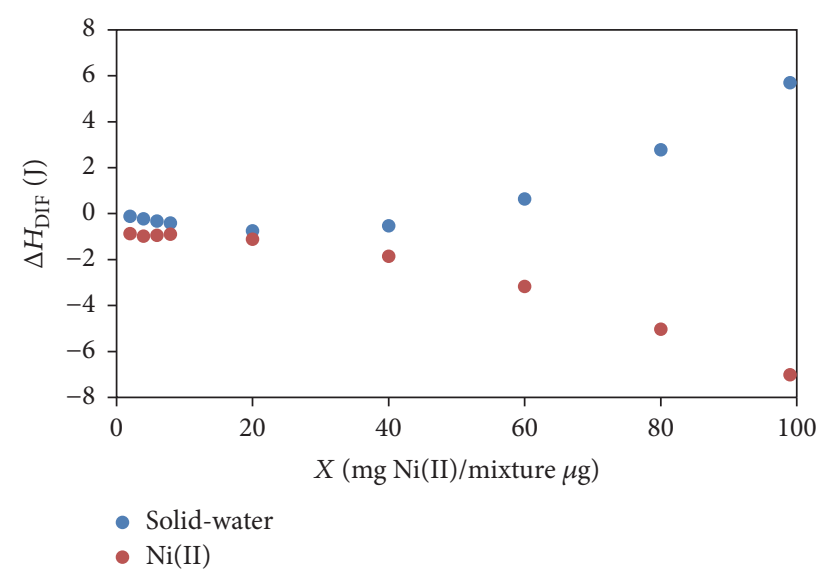

FIGURE 8: Change in the differential enthalpy (solid-solvent) and $\mathrm{Ni}(\mathrm{II})$ in function of the mass fraction of $\mathrm{Ni}(\mathrm{II})$ to the carbonized CC.

for low mass fractions changes in enthalpy are small and from a mass fraction of 40 the behaviors are larger and opposite.

\section{Conclusions}

Prepare four carbonized solids from corn cob with different oxygen groups contents in the surface. The surface area values of the solids are between 110 and $130 \mathrm{~m}^{2} \mathrm{~g}^{-1}$ and the total acidity is between 0.46 and $1.26 \mathrm{mmolg}^{-1}$.

From the determination of the immersion enthalpy of the carbonized solids in aqueous solutions of different $\mathrm{Ni}$ (II) concentration and assuming the relations of the mixtures thermodynamics, calculate the contribution of ion to the enthalpy total.

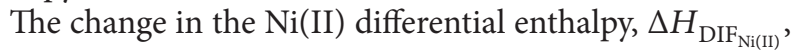
in the carbonized is between -0.87 and $-7.03 \mathrm{~J}$ which indicates an increase in the enthalpy change with the ion $\mathrm{Ni}(\mathrm{II})$ quantity.

$\Delta H_{\mathrm{DIF}_{\mathrm{N}(I I)}}$ is related with the carboxylic groups content and with the total acidity on the surface of the solid. It is noted for a mass fraction of $\mathrm{Ni}$ (II) in the mixture of 90 that in the carbonized less oxidized solids the enthalpy difference decreases and for solids with greater oxidation values the enthalpy differential is nearby, which indicates that the interactions of solid with ion in the mixture are intensified with the presence of oxygen groups.

The enthalpic contribution is calculated for the whole solid-solvent in the CC carbonized without treatment acid, with values between -0.12 and $2.78 \mathrm{~J}$ with an opposite behavior to that of the ion $\mathrm{Ni}(\mathrm{II})$ enthalpic contribution in the mixture, complying with the Gibbs-Duhem equation.

\section{Conflicts of Interest}

The authors declare that they have no conflicts of interest.

\section{Acknowledgments}

The authors acknowledge the framework agreement between the University of the Andes and the National University of Colombia and the act of agreement established by the Departments of Chemistry of both universities. The authors also acknowledge Project 3580 of Bank of Republic of Colombia for the partial fund to carry out this research.

\section{References}

[1] M. Y. Klotz and R. M. Rosenberg, "Chemical thermodynamics," in Basic Concepts and Methods, John Wiley \& Sons Inc., Hoboken, NJ, USA, 7th edition, 2008.

[2] I. Alonso, J. A. González, I. Garcia, and J. C. Cobos, “Thermodynamics of (ketone + amine) mixtures. Part XI. Excess molar enthalpies at $\mathrm{T}=298.15 \mathrm{~K}$ for the (1-propanol $+\mathrm{N}, \mathrm{N}, \mathrm{N}$ triethylamine+2-butanone) system," Journal of Chemical Thermodynamics, vol. 69, pp. 6-11, 2014.

[3] H. Arslan, "Determinations of enthalpy and partial molar enthalpy in the alloys Bi-Cd-Ga-In-Zn, Bi-Cd-Ga-Zn and AuCu-Sn," Materials Chemistry and Physics, vol. 153, pp. 384-389, 2015.

[4] R. Zhang, J. Chen, and J. Mi, "Excess molar enthalpies for binary mixtures of different amines with water," Journal of Chemical Thermodynamics, vol. 89, pp. 16-21, 2015.

[5] A. L. Myers and P. A. Monson, "Physical adsorption of gases: The case for absolute adsorption as the basis for thermodynamic analysis," Adsorption, vol. 20, no. 4, pp. 591-622, 2014.

[6] R. S. Neyband and H. Zarei, "A combined experimental and computational investigation of excess molar enthalpies of (nitrobenzene + alkanol) mixtures," Journal of Chemical Thermodynamics, vol. 80, pp. 119-123, 2015.

[7] A. Dębski and W. Gaşior, "Calorimetric studies and thermodynamic properties of liquid Ag-Ca alloys," Journal of Chemical Thermodynamics, vol. 77, pp. 159-166, 2014.

[8] J. Rouquerol, F. Rouquerol, P. Llewellyn, G. Maurin, and K. S. W. Sing, Adsorption by Powders and Porous Solids: Principles, Methodology and Applications, Oxford, London, UK, 2nd edition, 2013.

[9] J. Kaźmierczak, P. Nowicki, and R. Pietrzak, "Sorption properties of activated carbons obtained from corn cobs by chemical and physical activation," Adsorption, vol. 19, no. 2-4, pp. 273281, 2013.

[10] J. C. P. Melo, E. C. Silva Filho, S. A. A. Santana, and C. Airoldi, "Synthesized cellulose/succinic anhydride as an ion exchanger. Calorimetry of divalent cations in aqueous suspension," Thermochimica Acta, vol. 524, no. 1-2, pp. 29-34, 2011.

[11] P. Atkins and J. Paula, Physical Chemistry, Oxford University Press, London, UK, 8th edition, 2008.

[12] A. R. Cestari, E. F. S. Vieira, R. C. Silva, and M. A. S. Andrade, "Direct determinations of energetic parameters at chitosan/ $\mathrm{Cr}(\mathrm{VI})$ interfaces by means of immersion heat-conduction microcalorimetry," Journal of Colloid and Interface Science, vol. 352, no. 2, pp. 491-497, 2010.

[13] C. Moreno-Castilla, M. A. Álvarez-Merino, L. M. PastranaMartínez, and M. V. López-Ramón, "Adsorption mechanisms of metal cations from water on an oxidized carbon surface," Journal of Colloid and Interface Science, vol. 345, no. 2, pp. 461466, 2010. 
[14] V. C. Srivastava, I. D. Mall, and I. M. Mishra, "Competitive adsorption of cadmium(II) and nickel(II) metal ions from aqueous solution onto rice husk ash," Chemical Engineering and Processing: Process Intensification, vol. 48, no. 1, pp. 370-379, 2009.

[15] R. Fonseca-Correa, L. Giraldo, and J. C. Moreno-Piraján, “Trivalent chromium removal from aqueous solution with physically and chemically modified corncob waste," Journal of Analytical and Applied Pyrolysis, vol. 101, pp. 132-141, 2013.

[16] H. P. Boehm, "Some aspects of the surface chemistry of carbon blacks and other carbons," Carbon, vol. 32, no. 5, pp. 759-769, 1994.

[17] F. Stoeckli and T. A. Centeno, "On the characterization of microporous carbons by immersion calorimetry alone," Carbon, vol. 35, no. 8, pp. 1097-1100, 1997. 

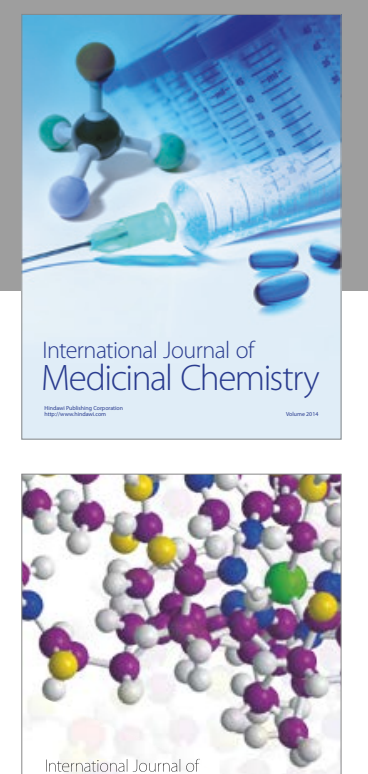

Carbohydrate Chemistry

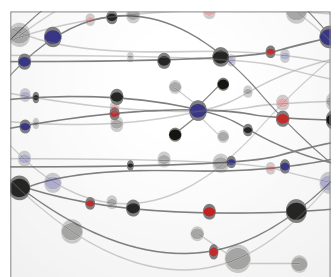

The Scientific World Journal
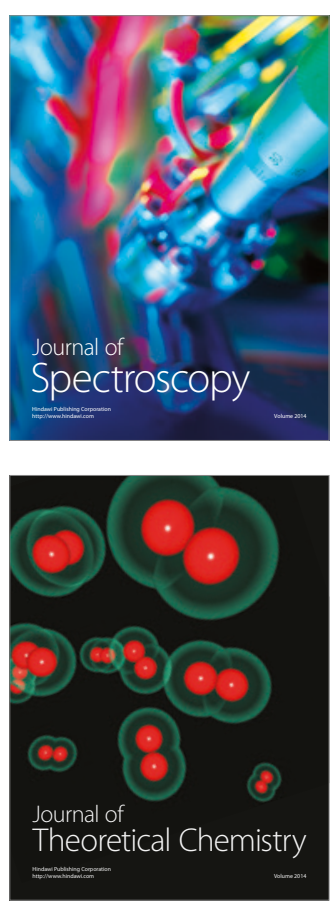
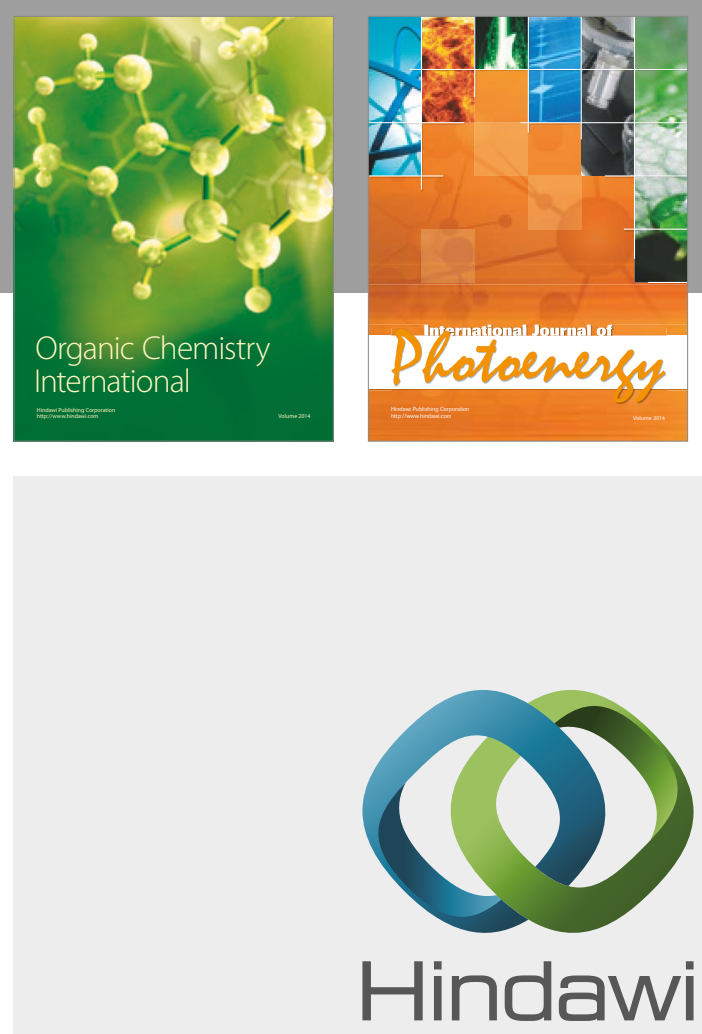

Submit your manuscripts at

https://www.hindawi.com

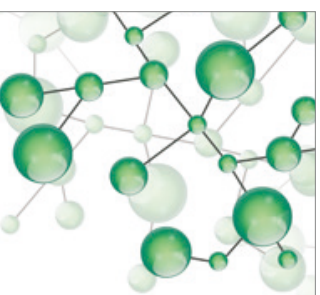

International Journal of

Inorganic Chemistry

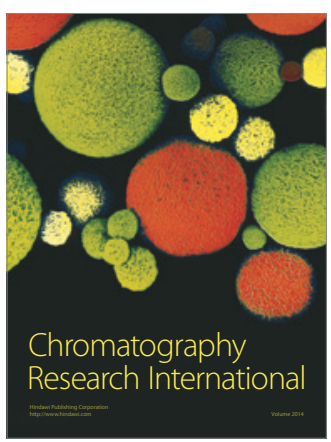

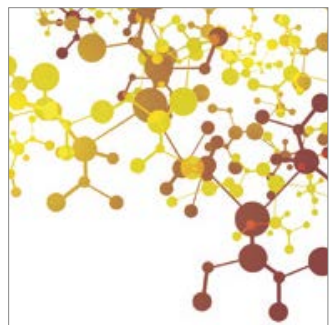

Applied Chemistry
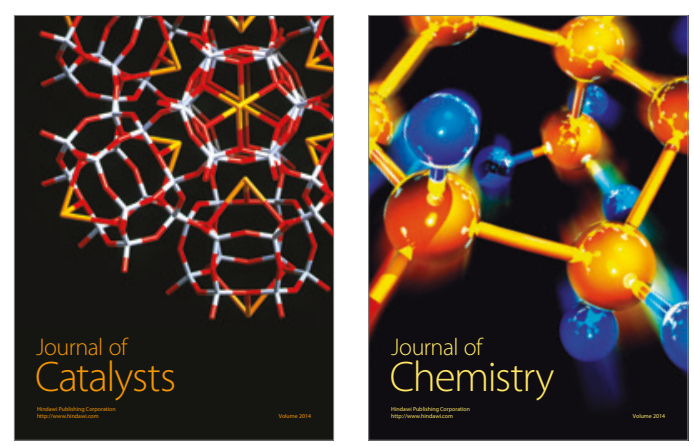
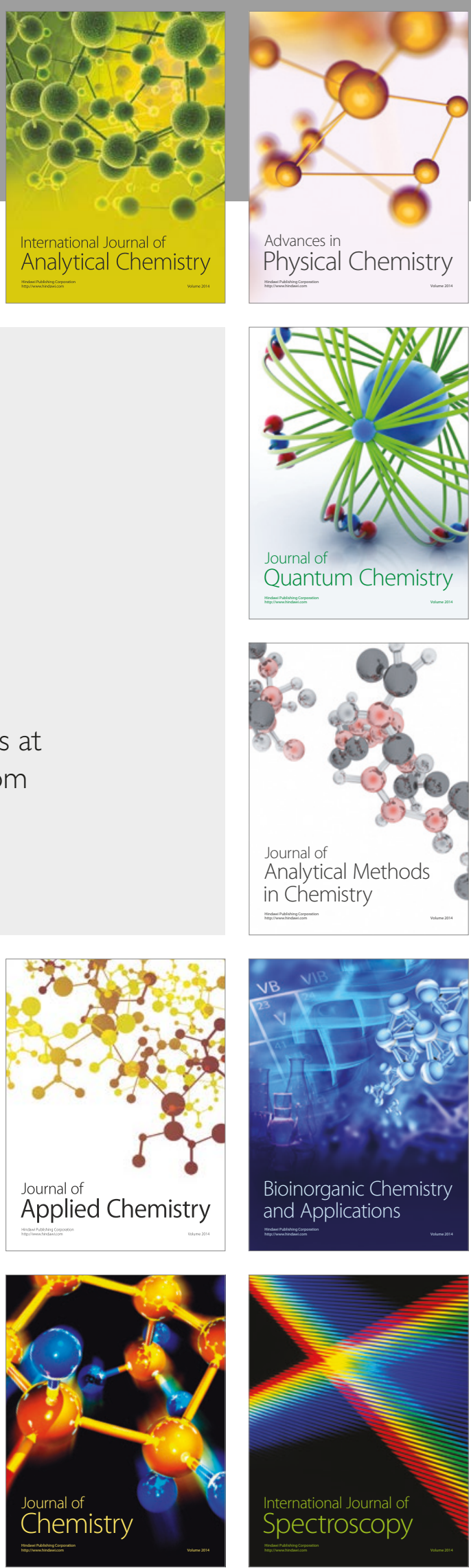